\title{
Presentació. \\ L'ensenyament de la geografia al segle XXI
}

Per tal d'actualitzar el coneixement acadèmic i presentar els nous debats i les noves tendències, DOCUMENTS D'ANÀLISI GEOGRÀFICA publica periòdicament números especials dedicats a l'ensenyament de la geografia. Els monogràfics anteriors van tenir molt bona acollida i estem convençuts que van repercutir en la millora i en la innovació en la didàctica d'aquesta matèria, tant en l'àmbit universitari com en altres àmbits educatius. Els orígens de l'interès que la revista ha mostrat en l'ensenyament de la geografia s'han de buscar en dues figures cabdals dintre d'aquest àmbit i que considerem que han estat els «mestres» del nostre camp. Ens referim a Enric Lluch i a Pilar Benejam. Des d'aquí, ens agradaria reconèixer i agrair la seva contribució. Com diu Pilar Benejam al seu darrer llibre (i que ressenya Xavier Fontich en aquest número), s'ha de tenir la humilitat i el plaer d'aprendre dels que ens han precedit i partir del seu discurs per repensar, reformular i millorar aquelles idees que han estat la base i el fonament de l'educació que volem, perquè si aquestes idees fossin noves, no es considerarien bàsiques (Benejam, 2014). La seva darrera obra és un recull de les reflexions sobre la teoria i la pràctica que l'autora ha anat acumulant durant les seves experiències professionals en escoles, instituts i a la universitat, i que ens resulten familiars a aquells que l'hem tingut de professora o com a companya de departament. Segurament, els primers fonaments de la didàctica de la geografia a Catalunya i a l'Estat espanyol deuen molt a la feina endegada a la Universitat Autònoma de Barcelona en el darrer terç del segle XX. Avui, que ja ens trobem a l'any 2017, podem dir que estem en un moment de canvi important en la 
didàctica de la geografia i que ens dirigim cap a una nova reconceptualització de la disciplina, més centrada a fer recerca i a reflexionar sobre com s'aprenen els coneixements escolars (és a dir, com es poden construir i reconstruir els conceptes i les idees geogràfiques de forma progressiva), i així poder dissenyar les estratègies d'ensenyament de forma pertinent (Reinfried, 2007).

L'objectiu d'aquest monogràfic és el d'aportar una visió actualitzada sobre les qüestions clàssiques principals de la didàctica de la geografia i destacar-ne també les noves. Així, ens preguntem: Què s'entén per didàctica de la geografia avui? Per què és important ensenyar geografia? Què s'ha d'ensenyar i com? Quina formació han de tenir els docents que n'imparteixen? Quins recursos hi ha a l'abast? Com ha afectat la tecnologia a l'educació, a la feina del professorat de geografia i a la disciplina geogràfica en general? Per respondre aquestes qüestions, al monogràfic, hi trobareu aportacions d'autors que investiguen sobre el que s'està treballant a Catalunya, a Espanya i al món, i que mostren quins són els debats més candents en aquests moments.

El primer debat que en volem destacar és la consideració de si la didàctica de la geografia és una nova disciplina o només una branca de la geografia que simplifica el coneixement disciplinari per ser transmès a l'escola. Reinfried i Hertig (2011), per exemple, consideren que la didàctica de la geografia és una disciplina científica que se situa entre tres camps científics: el de la geografia, el de l'educació i el de la psicologia. Per això afirmen que aquesta s'encarrega de conèixer els processos de com es crea personalment el coneixement geogràfic i, per tant, com s'ha d'ensenyar. Així, no es tracta d'una còpia simplificada de la disciplina geogràfica ni tampoc d'una didàctica específica, sinó d'una nova disciplina científica. En certa manera, nosaltres compartim aquesta visió, però hi trobem que manca el paper de la tecnologia, que avui ja no se'n pot considerar un element més, sinó un aspecte central. Si bé nosaltres ens decantem per models híbrids, hi ha propostes com el marc TPACK, de Koehler et al. (2015), que es decanten per un ús intensiu de la tecnologia, i això comporta que el professorat estigui format en sabers tecnologicopedagògics de la pròpia disciplina, en el nostre cas, de la geografia. A l'altre extrem, hi ha un corrent distint que ha agafat força al Regne Unit i que se centra en un altre debat que anomenen powerful knowledge ('coneixement poderós'). Aquesta idea parteix del realisme social i de les tesis de Michael Young (Young et al., 2015). Gemma Puig ha ressenyat el llibre de Young i n'assenyala que el principal argument que té és que un currículum que deixa de banda el saber disciplinari i no ofereix un coneixement poderós està ajudant a promoure la injustícia social. John Morgan, al seu article "Persevering with geography», se centra en l'anàlisi del coneixement poderós en l'ensenyament de la geografia. Morgan parteix d'una preocupació que està bastant estesa internacionalment i que troba que la formació que ha rebut el professorat al llarg de les darreres dècades ha incidit en la manera com cal ensenyar i no pas a tenir un bon coneixement disciplinari, perquè la tasca professional a l'escola també s'ha centrat a ensenyar el com i no pas el què. Davant d'aquesta tendència, l'autor es pregunta què és el que fa que un professor de geografia perseveri en la seva 
intenció de voler-se dedicar a la docència d'aquesta matèria. Morgan pren el Brèxit com una qüestió geogràfica complexa i d'actualitat per mostrar que un docent que vulgui treballar aquest tema a l'aula amb rigor i solvència necessita tenir un coneixement geogràfic conceptual específic i profund. Segons el seu parer, l'anàlisi de la formació inicial del professorat de les darreres tres dècades mostra que no té prou formació en contingut geogràfic i planteja què podria significar el retorn del coneixement disciplinari als programes de formació del professorat. Si bé, a Catalunya i a l'Estat espanyol, fa temps que hi ha veus que denuncien aquesta circumstància, hem de dir que la formació geogràfica està desdibuixada principalment en els graus universitaris d'educació infantil i primària, mentre que la formació disciplinària del professorat de secundària no hauria de ser problemàtica, si no fos perquè la major part d'ensenyants d'aquesta matèria prové de graus d'història. De totes maneres, al nostre país, encara no ha arribat aquesta onada que qüestiona el socioconstructivisme i que pretén retornar al coneixement disciplinari. Aquí, com mostra el llibre de Liceras i Romero (2016), que ressenya Jesús Velez, continuem amb la idea de construir una didàctica de les ciències socials socioconstructivista que sigui pluridisciplinar i que doni resposta a l'àrea curricular, però, en canvi, a la pràctica el que es fa és seguir amb un enfocament centrat en les didàctiques de la geografia, la història i la història de l'art per separat.

Un altre debat que trobem en aquest monogràfic és el que gira entorn de la qüestió sobre quin tipus de currículum és el més adequat per a la realitat del segle XXI. Péter Bagoly-Simó, al seu article «Exploring comparative curricular research in geography education", hi exposa que és convenient que es facin més comparatives curriculars i hi esbossa un marc analític que serveixi per confrontar els currículums de geografia de diferents països del món. En la seva proposta, hi analitza Alemanya i Romania i parteix del model curricular que s'ha anomenat Futur 3, desenvolupat per Young et al. (2015) i que suposa un retorn a un currículum centrat principalment en el coneixement (saber) i no pas en el desenvolupament de competències ni d'habilitats (saber fer), que correspondria al currículum de Futur 2 o socioconstructivista. El currículum de Futur 3 se centra en el coneixement especialitzat, el qual està generat per les comunitats d'investigació de la disciplina geogràfica i es contraposa al currículum de Futur 1 o tradicional, ja que veu el coneixement com a fal-lible, provisional i obert al canvi. Aquesta nova proposta de classificar els models curriculars en tres tipus de "Futurs» vol reemplaçar les propostes del segle XX, que principalment diferenciaven entre els enfocaments positivista, humanista i realista o crític (Johnston, 1986; Benejam, 1997; Morgan i Lambert, 2005). Però si no es desenvolupen més, no sembla que, a priori, hagin de reeixir.

El debat sobre el pes i/o rellevància que les tecnologies geoespacials, les tecnologies de la informació i comunicació (TIC) i les tecnologies de l'aprenentatge i el coneixement (TAC) han de tenir en l'ensenyament de la geografia s'evidencia en els dos textos dedicats al repàs de la producció científica a escala internacional i a escala nacional que s'ha portat a terme en els darrers anys. Rafael de Miguel, al seu article «La producción científica reciente en 
didáctica de la geografía a través de las sociedades geográficas. Declaraciones, publicaciones y proyectos a nivel nacional e internacional», presenta un recull de les principals activitats relacionades amb el foment de la investigació educativa que les diferents associacions científiques geogràfiques han portat a terme darrerament. Són interessants el recorregut i la síntesi que realitza dels principals documents produïts per la UGI-CGE, institució de la qual és membre i de qui destaca la Declaració Internacional sobre Educació Geogràfica de l'any 2016. De Miguel emfasitza l'impacte que les tecnologies de naturalesa geoespacial estan tenint actualment a l'aula. Per altra banda, Rosa Maria Medir i Salvador Calabuig, a «Darreres aportacions en l'ensenyament de la geografia a Catalunya i Espanya», realitzen una síntesi de la recerca a casa nostra. Comencen fent una anàlisi crítica del currículum actual de l'educació primària i secundària, $\mathrm{i}$ acaben amb la descripció de com avancen les experiències tecnològiques en didàctica de la geografia. També valoren els enfocaments que tracten la inclusió de la sostenibilitat, que han tingut un impacte moderat fins al moment. Així, en el nostre país no s'ha produït el que John Morgan (2012) ha anomenat "batalla per les idees», que polaritza la disciplina entre els partidaris d'un ensenyament de la geografia per la sostenibilitat i els que defensen centrar-se en les temàtiques tradicionals i no convertir la disciplina en un fundalisme verd. Meriam Boulahrouz Lahmidi desenvolupa aquest punt en la ressenya del llibre de Morgan (2012), titulat Teaching Secondary Geography as if the Planet Matters.

El monogràfic consta també de tres propostes específiques que pretenen fer avançar la didàctica de la geografia en àmbits específics. Jesús Granados Sànchez, a l'article «La formulación de buenas preguntas en didáctica de la geografía», distingeix les grans qüestions geogràfiques per ser tractades en l'educació obligatòria a la segona dècada del segle XXI. L'autor també enumera les principals característiques que han de tenir les preguntes per considerar-les com a bones i posa èmfasi en la importància de clarificar tipus de qüestions segons el nivell de pensament que suposen. Per últim, fa una proposta, que és el resultat de combinar taxonomies diferents, en què distingeix quatre nivells de preguntes segons l'estat cognitiu: de comprensió i retenció de la informació geogràfica; per al processament de la informació geogràfica; per a l'aplicació, la creació i l'avaluació del coneixement geogràfic, i metacognitives, per realitzar una autoreflexió sobre l'aprenentatge geogràfic. Roser Batllori i Joan Maria Serra proposen passar «D'ensenyar geografia a través del paisatge a educar en paisatge». Segons els autors, aquest nou enfocament pretén ser un procés per ajudar a promoure l'educació intel.lectual, l'educació emocional i per empènyer a actuar, com també una eina per ajudar els estudiants a créixer des del punt de vista personal. Els autors també descriuen el projecte Ciutat, territori i paisatge, el qual planteja com la ciutat estructura i transforma el territori d'arreu de Catalunya i com aquesta expansió afecta el paisatge. Stefano Malatesta i Jesús Granados Sánchez han treballat conjuntament per connectar la geografia dels infants amb l'ensenyament de la geografia i així enriquir aquests dos camps, que han caminat en paral.lel i separats. Segons els autors, les aportacions prin- 
cipals que les geografies dels nens i nenes poden fer a la didàctica són les següents: considerar que els nens i nenes són agents socioespacials; mostrar com es fa l'apropiació de l'espai a la infancia; conèixer les primeres representacions de l'experiència espacial que fan els nens i les nenes, i saber com són els llocs d'infancia de l'alumnat que s'educa.

El monogràfic també conté dues experiències didàctiques innovadores en l'ensenyament de la geografia, que han estat escollides per la seva originalitat. La primera és el projecte Geoactiva't, que es porta a terme al Departament de Geografia de la Universitat de Girona des de fa anys. L'objectiu que persegueix és acostar els universitaris del grau de Geografia, Ordenació del Territori i Gestió del Medi Ambient a la tasca docent de secundària i, alhora, presentar als estudiants de secundària conceptes, eines i mètodes de la geografia des d'una perspectiva experimental i dinàmica. Entre els èxits d'aquest projecte, en destaquen la motivació per aprendre que es genera entre l'alumnat de secundària, la possibilitat que té l'estudiant del grau de descobrir la tasca docent abans de seguir els estudis de postgrau i la promoció que es fa dels estudis del grau de Geografia en l'àmbit de l'educació secundària. La segona bona pràctica educativa se circumscriu a un institut d'educació secundària de l'àrea metropolitana de Barcelona. El professor Jordi Royo ens mostra com la creació de vídeos a la classe de geografia serveix per motivar l'alumnat d'entorns desfavorits i aprendre temes geogràfics complexos del seu barri.

Ens agradaria acabar aquesta introducció afirmant que, atesa la conjuntura del món actual, cal fer un replantejament o una revisió de l'ensenyament de la geografia i reivindicar-ne el seu paper en l'educació per comprendre i prendre consciència del món on vivim i per construir una ètica planetària. La didàctica de la geografia no és una metodologia, és un nou camp del saber que exposa molts elements conjuntament: el saber disciplinar, el saber que s'ensenya, el professorat que imparteix els coneixements, l'alumne que aprèn, les tecnologies geoespacials, les TIC i les TAC, els currículums que estableixen els governs, la formació inicial i contínua del professorat, etc. Un dels aspectes que estan canviant, i sobretot a partir de l'aparició de l'educació per la sostenibilitat, és entendre que l'educació integral holística de la persona no només ha d'incloure continguts conceptuals i aspectes cognitius, sinó que també ha de tenir en compte uns altres aspectes, com ara les emocions. Tot això comporta uns canvis estructurals importants: la universitat ha de continuar fent recerca $\mathrm{i}$ assegurar-se que els resultats arriben i influeixen en les reformes educatives i en el disseny del currículum; els acadèmics han d'aportar models didàctics actualitzats que ajudin el professorat a resoldre els problemes amb què s'enfronten a l'actualitat i a explorar millores per al futur; l'exercici professional dels mestres demana un grau més elevat de compromís per part seva i uns estils diferents d'ensenyar que fomentin la tasca en equip, la participació de l'alumnat i l'ús de les tecnologies digitals, a fi d'aconseguir que el treball sigui col-laboratiu i que es realitzi mitjançant la utilització de noves metodologies i la promoció de les competències personals. 


\section{Agraïments}

Aquest número ha rebut el suport econòmic del Departament de Didàctiques Específiques de la Universitat de Girona, de l'Institut de Recerca Educativa de la Universitat de Girona i de la Facultat de Ciències de l'Educació de la Universitat Autònoma de Barcelona.

\section{Referències bibliogràfiques}

Benejam, P. (1997). «Las finalidades de la educación social». A: Benejam, P. i PAGÈS, J. (coord.) (1997). Enseñar y Aprender Ciencias Sociales, Geografía e Historia en la Educación Secundaria. Barcelona: Institut de Ciències de l'Educació. Universitat Autònoma de Barcelona / Horsori, 33-51.

- (2014). Quina educació volem? Barcelona: Rosa Sensat, Col-lecció Referents, 6.

Johnston, R. (1986). On Human Geography. Oxford: Blackwell.

Koehler, M.J.; Mishra, P. i CAin, W. (2015). «¿Qué son los saberes tecnológicos y pedagógicos del contenido (TPACK)?». Virtualidad, Educación y Ciencia, 10 (6), 9-23.

Liceras Ruiz, Á. i Romero Sánchez, G. (coords.) (2016). Didáctica de las Ciencias Sociales: Fundamentos, contextos y propuestas. Madrid: Pirámide.

MoRGan, J. (2012). Teaching secondary geography as if the planet matters. Londres: Routledge.

MORGAN, J. i LAMBERT, D. (2005). Geography: Teaching school subjects. Londres: Routledge, 11-19.

REINFRIED, S. (2007). «Educational reconstruction: A key to progress in geoscience teaching and learning». Geographie und ihre Didaktik, 35 (4), 232-243.

ReINFried, S. i HerTig, P. (2011). "Geographical education: How human-environment-society processes work». A: UNESCO-EOLSS JoINT COMMITTEE (eds.). Encyclopedia of Life Support Systems (EOLSS) [en línia]. Oxford, UK: UNESCO, Eolss Publishers. <http://www.eolss.net>.

Young, M.; Lambert, D.; RoberTs, C. i Roberts, M. (2015). Knowledge and the Future School: Curriculum and social justice. Londres: Bloomsbury.

Jesús Granados Sánchez Roser Batllori i Obiols Universitat de Girona 